\title{
Evaluation of Hepatosplenomegaly and Liver Function Tests in 102 Brucellosis Cases
}

Serhat UYSAL ${ }^{1}$, Fatih DANA², Meltem IŞIKGÖZ ${ }^{1}$, Erkan KISMALI², Oğuz Reşat SiPAHi ${ }^{1}$, Hüsnü PULLUKÇU ${ }^{1}$, Tansu YAMAZHAN ${ }^{1}$, Sercan ULUSOY ${ }^{1}$

\footnotetext{
${ }^{1}$ Ege Üniversitesi Tıp Fakültesi, Enfeksiyon Hastalıkları ve Klinik Mikrobiyoloji Anabilim Dalı, İzmir, Türkiye

${ }^{1}$ Department of Infectious Diseases and Clinic Mikrobiology, Faculty of Medicine, Ege University, Izmir, Turkey

2 Ege Üniversitesi Tıp Fakültesi, Radyoloji Anabilim Dalı, İzmir, Türkiye

${ }^{2}$ Department of Radiology, Faculty of Medicine, Ege University, Izmir, Turkey
}

\section{ÖZET}

Giriş: Bruselloz karaciğer tutulumu dahil olmak üzere birçok organı tutabilen sistemik bir hastalıktır. Bu çalışmada kliniğimizde takibi yapılan brusellozlu olgularda hastalığın karaciğer ve dalak üzerine olan etkileri irdelenmiştir.

Materyal ve Metod: Bu çalışmada kliniğimizde Temmuz 2006 ile Ekim 2014 tarihleri arasında takip ettiğimiz bruselloz olguları geriye dönük taranmıştır. Bruselloz tanısı mikrobiyolojik kültür olumluluğu ve/veya Wright aglütinasyon testinin 1/160 ve üzeri titrede saptanması ile konuldu.

Bulgular: Çalışmaya 102 olgu [43 kadın (\%42.2), 59 erkek (\%57.8), yaş ortalaması 47.1 \pm 16 ] dahil edilmiştir. Seksen iki (\%80.3) hastada 1/160 ve üzeri wright aglütinasyon testi olumluluğu ile üç hastada tanı wright aglütinasyon testi olumsuz olmasına karşın anti-human globülin testi ile tanı konuldu. On yedi (\%16.7) hastanın tanısı ise sadece kan kültürü olumluluğu ile konuldu. En sık ilk üç semptom ateş (\%63.7), halsizlik (\%48) ve bel-kalça ağrısıydı (\%48). Ultrasonografi ile hepatomegali ve splenomegali sırasıyla 16 (\%15.8) ve 19 (\% 18.8) olguda tespit edildi. Hastalarda AST, ALT, ALP, GGT ve toplam bilirubin testlerinde yükseklik sırasıyla \%23.8, \%24.8, \%26.8, \%36.6, \%12.9 oranında saptandı. Kırk iki (\%41.2) hastada bulgu veren karaciğer ilişkili patolojiye rastlanmadı. Herhangi bir patolojiye rastlanmayan hastaların yaş ortalaması $51.1 \pm 14.9$ yıl iken, diğer hastalarda $44.3 \pm 16.3$ yıl olarak bulundu $(p=0.035)$. Tüm hastalarda tedavi sonunda karaciğer fonksiyon testlerinde düzelme saptandı. Hastaların hiçbirinde ciddi yan etki görülmemiştir.

Sonuç: Bruselloz öncelikle retiküloendotelyal sistemi etkileyerek karaciğer hasarına da neden olabilen ama tedaviye yanıt oranı yüksek zoonotik bir hastalıktır. Bununla birlikte olgularımızın önemli kısmında ultrasonografi ile karaciğer ilgili herhangi bir patoloji saptanmamıştır. Ülkemiz gibi brusellozun yaygın görüldüğü bölgelerde karaciğer bulgusu olmayan olgularda da bruselloz akılda tutulmalıdır. 
Anahtar kelimeler: Bruselloz, hepatomegali, karaciğer fonksiyon testleri, splenomegali

Geliş Tarihi: 07.11.2014 • Kabul Ediliş Tarihi: 26.12.2014 • Yayınlanma Tarihi: 31.12.2014

\section{ABSTRACT}

Introduction: Brucellosis is a systemic infection which in volves many organs including liver. In this study, it was aimed to review the hepatosplenic findings in allcases followed up in our clinic with the diagnosis of brucellosis.

Materials and Methods: Allcases, we followed up in our clinic between July 2006 and October 2014 with the diagnosis of brucellosis, were reviewed retrospectively. Cases with microbiological culture confirmation and/or Wright agglutination test positivity with a titer of $1 / 160$ or higher were considered brucellosis.

Results: There were a total of 102 cases meeting the inclusion criteria (43 female (42.2\%), 59 male (57.8\%), aged $47.1 \pm 16)$. Eighty-two (80.3\%) patients had a titer of $1 / 160$ or more Wright agglutination test positivity. Three patients had negative Wright agglutination test but had anti-humanglobulin test positivity. Seventeen $(16.7 \%)$ patients were diagnosed with only blood culture. The most common three symptoms were fever $(63.7 \%)$, weakness $(48 \%)$ and back pain $(48 \%)$. Hepatomegaly and splenomegaly were determined with ultrasonography in $16(15.8 \%)$ and $19(18.8 \%)$ cases, respectively. About $23.8 \%, 24.8 \%, 26.8 \%$, $36.6 \%$, and $12.9 \%$ of the patients had elevated levels of AST, ALT, ALP, GGT and total bilirubin, respectively. Forty-two (41.2\%) patients had no remarkable pathology in the liver. Mean age of the cases without a remarkable liver pathology was $51.1 \pm 14.9$; whereas, mean age of the rest of the cases was $44.3 \pm 16.3(p=0.035)$. Liver function tests improved in all cases with treatment. There was no severe adverse drug reaction during treatment.

Conclusion: Brucellosis is a zoonotic disease that primarily affects the reticuloendothelial system, and may cause liver damage. Its response to treatment is high. However, there was no pathology in ultrasonography in majority of the cases. In a brucellosis endemic country such as Turkey, it must be kept in mind that the disease may present without significant liver involvement.

Key words: Brucellosis, hepatomegaly, liver function tests, splenomegaly

Received: 07.11.2014 • Accepted: 26.12.2014 • Published: 31.12.2014

\section{GiRiș}

Bruselloz Türkiye'nin de dahil olduğu birçok Akdeniz ülkesinde endemik bir zoonotik hastalıktır ${ }^{[1]}$. Veteriner hekimlik veya çiftçilik gibi mesleki maruz kalma dışında en sık bulaş pastörize edilmemiş süt ve süt ürünleri ile olmaktadır ${ }^{[1,2]}$. Hastalık çok çeşitli semptom ve bulgular ile karşımıza çıkabilmektedir ${ }^{[3]}$. Bu hastalığa neden olan brusella türleri gram-negatif kokobasil yapısında aerop bakterilerdir ve hücre içinde kümelenmeye eğilimlidir ${ }^{[4]}$. Birçok hastalığı taklit edebilen bruselloz; pek çok sistemi de etkileyebilir. Retiküloendotelyal sistemi de etkilediğinden karaciğer ve dalak tutulumu da sıkça görülür ${ }^{[5]}$. Bu çalışmada kliniğimizde takibi yapılan bruselloz hastalarında, brusellozun karaciğer ve dalak üzerine olan etkileri irdelenmiştir.

\section{MATERYAL ve METOD}

Kliniğimizde Temmuz 2006-Ekim 2014 tarihleri arasında takip ettiğimiz bruselloz hastaları retrospektif taranmıştır. Bruselloz tanısı, mikrobiyolojik kültürde brusella türlerinin kan doku ve aspirasyon kültürlerinden izole edimesi ve/veya wright aglütinasyon testinde (SWAT) 1/160 ve üzeri titrelerde olumlu olması ve şiddetli klinik şüphe varlığında olumsuz SWAT ve olumlu Bose Bengal lam aglütinasyon testi (RB) varlığında Anti-Human globülin testi (AHG) olumluluğu ile konulmuştur. Olguların başvuru sırasında ölçülen en yüksek vücut sıcaklığı, aspartataminotransferaz (AST), alaninaminotransferaz (ALT), alkalenfosfataz (ALP), gama glutamiltransferaz (GGT), toplam/direkt/indirekt bilirubin, batın içi ultrasonografi (USG) değerlendirme sonucunda tespit edilen karaciğer ve dalak boyut anormallikleri ve tüm değerlendirmeler sonucunda karaciğer ile ilişkili herhangi bir bozukluğu olmayan hastalar kaydedildi. Batın USG ile granülomatöz hepatit, hepatik apse ve diffüz hepatit tanısı konuldu ${ }^{[6]}$. Klinik hepatit tanısı için karaciğer fonksiyon testlerinin normalin üst sınırının beş kat üzerine çıkması kriter olarak belirlendi ${ }^{[6]}$. Bu ölçümler için hastanemizdeki normal değerler Tablo 
1 'de verilmiştir. Tedavi edilen hastaların aldıkları rejimler, tedavi sırasında gelişen yan etkiler ve tedavi bitiminde yapılan karaciğer fonksiyon ve görüntüleme yöntemleri kaydedilmiştir. Bakılan laboratuvar testlerinin normal değerleri üzerinde tespit edilen hastalar ile diğer hastalar analiz edilmiştir.

\begin{tabular}{lc}
\hline Tablo 1. Normal laboratuvar bulguları & \\
\hline Test & Normal Değer \\
\hline SGOT (AST) & $<35 \mathrm{U} / \mathrm{L}$ \\
SGPT (ALT) & $<45 \mathrm{U} / \mathrm{L}$ \\
Alkalen fosfataz & $<129 \mathrm{U} / \mathrm{L}$ \\
GGT & $<55 \mathrm{U} / \mathrm{L}$ \\
Toplam protein & $<8.3 \mathrm{~g} / \mathrm{dL}$ \\
Albümin & $<5.2 \mathrm{~g} / \mathrm{dL}$ \\
Toplam bilirubin & $<1 \mathrm{mg} / \mathrm{dL}$ \\
Direkt bilirubin & $<0.25 \mathrm{mg} / \mathrm{dL}$ \\
Indirekt bilirubin & $<0.9 \mathrm{mg} / \mathrm{dL}$ \\
\hline
\end{tabular}

\section{BULGULAR}

Çalışmaya dahil edilme kriterlerini karşılayan 43 (\%42.2)'ü kadın toplam 102 olgu (yaş ortalaması 47.1 \pm 16 yıl) vardır. Seksen iki (\%80.3) hastada tanı 1/160 ve üzeri SWAT olumluluğu ile konulmuştur. Tanı 17 (\% 16.7) hastada sadece kan kültürü olumluluğu ile üç hastada RB olumlu olduğu halde SWAT olumsuz olması üzerine istenilen AHG testinin olumlu olması ile konulmuştur. Kan kültürü alınan 65 olgudan 41 'inde Brucella spp. izole edilmiştir. Hastaların başvuru semptomlarının sıkığı Tablo 2'de verilmiştir. Kırk bir hastada

\section{Tablo 2. Semptomların dağılımı}

\begin{tabular}{lc} 
Semptom & Yüzde (\%) \\
\hline Ateş & 63.7 \\
Bel ve kalça ağrısı & 48.0 \\
Halsizlik & 48.0 \\
Sağ üst kadran ağrısı & 30.4 \\
Kilo kaybı & 19.6 \\
İştahsızlık & 15.7 \\
Terleme & 11.8 \\
Baş ağrısı & 7.8 \\
Bulantı-kusma & 5.9
\end{tabular}

\begin{tabular}{lc} 
Tablo 3. Laboratuvar bulguları (ortalama \pm standart \\
sapma) \\
Lökosit $\left(\mathrm{mm}^{3}\right)$ & $6386 \pm 2490$ \\
Hemoglobin, $(\mathrm{g} / \mathrm{dL})$ & $12.6 \pm 1.6$ \\
Trombosit, $\left(\mathrm{mm}^{3}\right)$ & $240990 \pm 89230$ \\
CRP $(\mathrm{mg} / \mathrm{L})$ & $2.5 \pm 3.0$ \\
ESR $(\mathrm{mm} / \mathrm{h})$ & $31.4 \pm 27.8$ \\
ALT (IU/L) & $40.2 \pm 45.2$ \\
AST (IU/L) & $31.9 \pm 24.9$ \\
ALP (IU/L) & $113.7 \pm 82.6$ \\
GGT (IU/L) & $68.6 \pm 78.1$ \\
Kreatinin (mg/dL) & $0.92 \pm 0.64$ \\
Toplam protein (g/dL) & $7.3 \pm 1.90$ \\
Albumin (g/dL) & $3.8 \pm 0.43$ \\
Toplam bilirubin (mg/dL) & $0.69 \pm 0.82$ \\
Direkt bilirubin (mg/dL) & $0.34 \pm 0.71$ \\
\hline & \\
\hline
\end{tabular}

fizik muayene ve laboratuvar testlerinde karaciğer ile ilgili patoloji saptanmadığı için USG istenmemiştir. Şüpheli bulguları olan 61 hastaya USG çekilirken, hepatomegali ve splenomegali sırasıyla 16 (\%15.8) ve 19 (\%18.8) olguda tespit edilmiştir. Batın USG ile hepatomegali tespit edilenlerin ( $\mathrm{n}: 16)$ karaciğer boyutu ortalama $166.27 \pm 11.5 \mathrm{~mm}$ ve splenomegali tespit edilenlerin ( $\mathrm{n}: 19)$ dalak boyutu ortalama $151.3 \pm 15.4$ $\mathrm{mm}$ olarak bulundu. Hastaların hiçbirinde USG'de granülomatöz hepatit, diffüz hepatit ve hepatik apse bulgusuna rastlanılmamıştır. Hastaların başvuru sırasında tespit edilen laboratuvar testleri Tablo 3'te özetlenmiştir. Hastaların AST, ALT, ALP, GGT ve total bilirubin seviyelerinde yükseklik tespit edilme sıklığı sırasıyla \%23.8, \%24.5, \%26.8, \%36.6, \%12.9 olarak bulunmuştur. Yükseklik tespit edilen hastalarda bulunan değerlerin ortalamaları Tablo 4'te verilmiştir. Diğer

\section{Tablo 4. Yükseklik tespit edilen olgularda ortalamalar}

\begin{tabular}{lc} 
Laboratuvar Değeri & $\begin{array}{c}\text { Ortalama } \pm \\
\text { standart sapma }\end{array}$ \\
\hline ALT (IU/L) & $97.5 \pm 62.9$ \\
AST (IU/L) & $65.3 \pm 31.2$ \\
ALP (IU/L) & $185.9 \pm 130.3$ \\
GGT (IU/L) & $132.4 \pm 94.2$ \\
Toplam bilirubin (mg/dL) & $1.8 \pm 1.7$ \\
\hline
\end{tabular}


parametrelerde anlamlı yükselme görülmemiştir. Kırk iki (\% 41.2) hastada yapılan bütün incelemeler (AST, ALT, ALP, GGT, total bilirubin, direkt bilirubin ve fizik muayene veya batın USG) sonucunda karaciğerde hiçbir patolojiye rastlanılmadı. Herhangi bir patolojiye rastlanılmayan hastaların yaş ortalaması $51.1 \pm 14.9$ yıl iken, diğer hastalarda $44.3 \pm 16.3$ yıl olarak bulundu $(p=0.035)$. Batın USG yapılan hastalar içerisinde AST, ALT, ALP, GGT, total bilirubin ve direkt bilirubinin normal bulunduğu toplam 17 (\%27.9) hasta vardır. Hiçbir olgumuzda fulminan hepatit gibi ciddi karaciğer yetmezliği görülmedi. AST, ALT, ALP, GGT ve total bilirubin testlerinde yükseklik ve (fizik muayene veya batın USG'de) hepatomegali tespit edilen 60 hastadan $41^{\prime} \mathrm{i}$ erkek iken herhangi bir patolojiye rastlanılmayan 42 hastadan 24 'ü kadındı $(p=0.010)$. Tüm hastalar antibiyotik tedavisi aldı. Mortal seyirli olguya rastlanmadı. Tedavi ile ilişkili karaciğer test artışları ve ciddi yan etki tespit edilmedi. Tüm hastaların tedavi sonrası üçüncü ayda bakılan karaciğer fonksiyon testleri normal olarak bulundu.

\section{TARTIȘMA}

Bruselloz, Akdeniz kıyılarında ve Ortadoğu'da endemik seyreden bir hastalıktır. Özellikle enfekte hayvanlar ile temas ve dekontamine süt ve süt ürünleri ile bulaş sık görülmektedir ${ }^{[1,2]}$. Çalışmamızda tespit edilenlerin yaş ortalaması $47.1 \pm 16$ bulunmuştur. Çocukluk çağı üzerine olan çalışmalar haricinde ülkemizde yapılan benzer çalışmalara bakıldığında yaş ortalaması 32 ile 48 arasında değişmektedir ${ }^{[7-9]}$. Tanıların çoğu (\%80.3) ilk etapta seroloji sonucu ile konulmuş ve toplam 41 (\%40.1) hastada kültürde Brusella türleri izole edilmiştir. AHG testi ile tanı alan toplam üç (\%2.9) hasta vardır. RB olumlu bulunduğu ve SWAT olumsuz bulunduğu şiddetli klinik şüphe varlığında $A H G$ istenmesi faydalı olacaktır.

Bu seride görülen en sık ilk üç klinik bulgu ateş, bel-kalça ağrısı ve halsizlik olarak bulundu. Fakat birçok başka çalışmada bu sıralama değişmekte ve oranları artmaktadır ${ }^{[5,6,8]}$. Hastanemizin bölgemizdeki son referans merkez olması ve buna bağlı olarak daha az komplike olguların önceki merkezlerde tedavi edilmiş olma olasılığı nedeniyle; çalışmamızdaki ateş, belkalça ağrısı ve halsizlik bulguları nispeten daha az görülmüş olabilir.

Brusellozda karaciğer tutulumu sıkça görülmekte- dir. Brusellozun karaciğer tutulumları sırasıyla diffüz hepatit, granülomatöz hepatit ve nadiren de hepatik brusellomadır ${ }^{[10]}$. Bazen de tedavi amaçlı verilen ilaca bağlı hepatotoksisiteye rastlanılmaktadır fakat bu durum \%2-3 ile nadir karşımıza çıkmaktadır ${ }^{[5,7,11]}$. Hepatomegalinin bazı çalışmalarda \%4.6 iken bazı çalışmalarda ise \%63 seviyelerine yükseldiği görülmektedir ${ }^{[6,7]}$. Bu çalışmada da literatür ile uyumlu olarak 16 (\%15.8) olguda hepatomegali tespit edilmiştir. Çalışmamızda splenomegali 19 (\%18.8) olguda tespit edilmişti. Ülkemizde yapılan birçok çalışmada \%14.5 ile \%42 arasında karşılaşıldığı görülmektedir ${ }^{[5,12]}$. Hepatomegali ve splenomegali hastalığın şiddetine, kronik olup olmadığına ve ilgili organlarda primer tutulum varlığına göre değişmektedir. Çeşitli serilerde bruselloz tedavisi ile ilişkili çeşitli ciddi komplikasyonlar nadir de olsa belirtilmektedir. Örneğin; Sayın Öztürk Engin ve arkadaşları; Marmara çalışmasında \%4 oranında tedavi sebepli yan etkiden bahsetmişlerdir ${ }^{[6]}$. Fakat hastalarımızın tedavileri esnasında herhangi bir ciddi yan etki ve istenmeyen olay ile karşılaşılmamıştır.

Hastaların yaklaşık \%41'inde başvuru anında ve sonrasında da karaciğer ile ilgili herhangi bir patolojiye rastlanmadığı dikkati çekmektedir. Karaciğer ile ilişkili anlamlı patolojik bulgu tespit edilen hasta oranı yaklaşık \%59'dur. Karaciğer ile ilişkili anlamlı patolojik bulguların \%87 ile \%21 arasında tespit edildiği bilinmekte$\operatorname{dir}^{[1,5,6]}$. Bu nedenle bruselloz tanı, tedavi ve izleminde karaciğer değerlendirmelerinin itina ile yapılması karaciğer tutulumu olmayan olgularda da akılda tutulması uygun olacaktır.

Çalışmanın retrospektif olması, katılan tüm hastaların USG tetkikinin olmaması, tüm KCFT yüksekliği tespit edilen hastalarda USG ve tüm hepatomegali ve/ veya splenomegali tespit edilen hastalarda da laboratuvar testlerinin bulunmayışı, USG bulguları ile laboratuvar arasındaki ilişkiyi irdeleme açısından çalışmayı kısıtlayıcı durumlardır.

Bruselloz öncelikle retiküloendotelyal sistemi etkileyerek karaciğer hasarına da neden olabilen ama tedaviye yanıt oranı yüksek zoonotik bir hastalıktır. Bununla birlikte olgularımızın önemli kısmında USG ile karaciğerle ilgili herhangi bir patoloji saptanmamıştır. Ülkemiz gibi brusellozun yaygın görüldüğü bölgelerde karaciğer bulgusu olmayan olgularda da bruselloz akılda tutulmalıdır. 


\section{KAYNAKLAR}

1. Tasbakan MI, Yamazhan T, Gokengin D, Arda B, Sertpolat $M$, Ulusoy $S$, et al. Brucellosis: A retrospective evaluation. Trop Doct 2003;3:151-3.

2. Chomel BB, DeBess EE, Mangiamele DM, Reilly KF, Farver TB, Sun RK, et al. Changing trends in the epidemiology of human brucellosis in California from 1973 to 1992: A shift toward foodborne transmission. J Infect Dis 1994;5:1216-23.

3. Young EJ. An overview of human brucellosis. Clin Infect Dis 1995;2:283-9.

4. Aydemir Ş. The Pathogen: Brucella species. Turkiye Klinikleri J Inf Dis-Special Topics 2012;5:8-10.

5. Buzgan T, Karahocagil MK, Irmak H, Baran Al, Karsen H, Evirgen $O$, et al. Clinical manifestations and complications in 1028 cases of brucellosis: A retrospective evaluation and review of the literature. Int $J$ Infect Dis 2010;6:11.

6. Ozturk Engin D, Erdem H, Gencer S, Kaya S, Baran Al, Batirel $A$, et al. Liver involvement in patients with brucellosis: Results of the Marmara study. Eur J Clin Microbiol Infect Dis 2014;7:1253-62.

7. Demiroglu YZ, Turunc T, Aliskan H, Colakoglu S, Arslan H. Brucellosis: Retrospective evaluation of the clinical, laboratory and epidemiological features of 151 cases. Mikrobiyol Bul 2007;4:517-27.
8. Kursun E, Turunc T, Demiroglu Y, Arslan H. Evaluation of four hundred and forty seven brucellosis cases. Intern Med 2013;7:745-50.

9. Kokoglu OF, Hosoglu S, Geyik MF, Ayaz C, Akalin S, Buyukbese MA, et al. Clinical and laboratory features of brucellosis in two university hospitals in Southeast Turkey. Trop Doct 2006;1:49-51.

10. Young EJ, Hasanjani Roushan MR, Shafae S, Genta RM, Taylor SL. Liver histology of acute brucellosis caused by Brucella melitensis. Hum Pathol 2014;10:2023-8.

11. Akritidis N, Tzivras M, Delladetsima I, Stefanaki S, Moutsopoulos HM, Pappas G. The liver in brucellosis. Clin Gastroenterol Hepatol 2007;9:1109-12.

12. Mousa AR, Elhag KM, Khogali M, Marafie AA. The nature of human brucellosis in Kuwait: Study of 379 cases. Rev Infect Dis 1988;1:211-7.

\section{Yazışma Adresi /Address for Correspondence}

Dr. Serhat UYSAL

Ege Üniversitesi Tıp Fakültesi,

Enfeksiyon Hastalıkları ve Klinik Mikrobiyoloji Anabilim Dalı

İzmir, Türkiye

E-posta: drserhatuysal@gmail.com 